\title{
Mutagenicity of aryl propylene and butylene oxides with Salmonella
}

\author{
L.B. Rosman, V. Gaddamidi and J.E. Sinsheimer \\ College of Pharmacy, University of Michigan, Ann Arbor, MI $48109-1065$ (U.S.A.)
}

(Received 23 February 1987)

(Revision received 20 April 1987)

(Accepted 1 May 1987)

Keywords: Aryl propylene oxides; Propylene oxides; Butylene oxides; Aryl butylene oxides; ( $S$ typhimurium Ames tests).

\section{Summary}

10 aryl propylene oxides and 6 aryl butylene oxides were synthesized. Dose-mutagenicity relationships were studied for these compounds and for 1,2-epoxybutane, using both the preincubation and plate incorporation Ames tests with Salmonella typhimurium strains TA100 and TA1535. Structure-mutagenicity relationships were further examined by concurrent testing at single doses with the plate incorporation assay in strain TA100. In both series of compounds, mutagenicity showed very weak correlation to chemical reactivity, molar volume and partition values. However, all compounds were mutagenic in at least one system with the propylene oxides being more mutagenic than the corresponding butylene oxide derivatives. The naphthyl derivatives in each series were the most mutagenic.

Sugiura et al. (1978a, b; 1981) and Tamura et al. (1982) have reported structure-mutagenicity relationships for styrene oxide derivatives. As part of our interest in such relationships for aliphatic epoxides we have studied a series of phenylglycidyl ethers (Neau et al., 1982) and extended the styrene oxide studies to include a series of parasubstituted $\alpha$-methylstyrene oxide derivatives (Rosman et al., 1986). In all the above studies, the electron donating or withdrawing capacity, as measured by Hammett values of the aromatic substituents, could be related to the mutagenicity of the epoxides in the Ames procedure (Maron and Ames, 1983). However, in our study of the mutagenicity of the $\alpha$-methylstyrene oxides and in

Correspondence to: Dr. J.E. Sinsheimer, College of Pharmacy, University of Michigan, Ann Arbor, MI 48109-1065 (U.S.A.). the study of Tamura et al. (1982) on styrene oxides, molecular volume as measured by van der Waals volume (Moriguchi et al., 1976) was the most important variable in multiple regression analyses of possible factors influencing the mutagenicity of these compounds.

It is the purpose of the present investigation to extend such studies to a series of aryl propylene and butylene oxides in order to examine the relative importance of molecular volume as well as electronic and partition effects on the mutagenicity of these compounds, where the phenyl-substituent effects are further removed from the oxirane ring than is the case with the styrene oxides.

In the butylene oxide series, only 1,2-epoxybutane has been previously assayed for mutagenicity in Salmonella (Canter et al., 1986; Gervasi et al., 1985; Chen et al., 1975; Hemminki et al., 1980; Katz et al., 1980; Rosenkranz and Speck, 1976; 


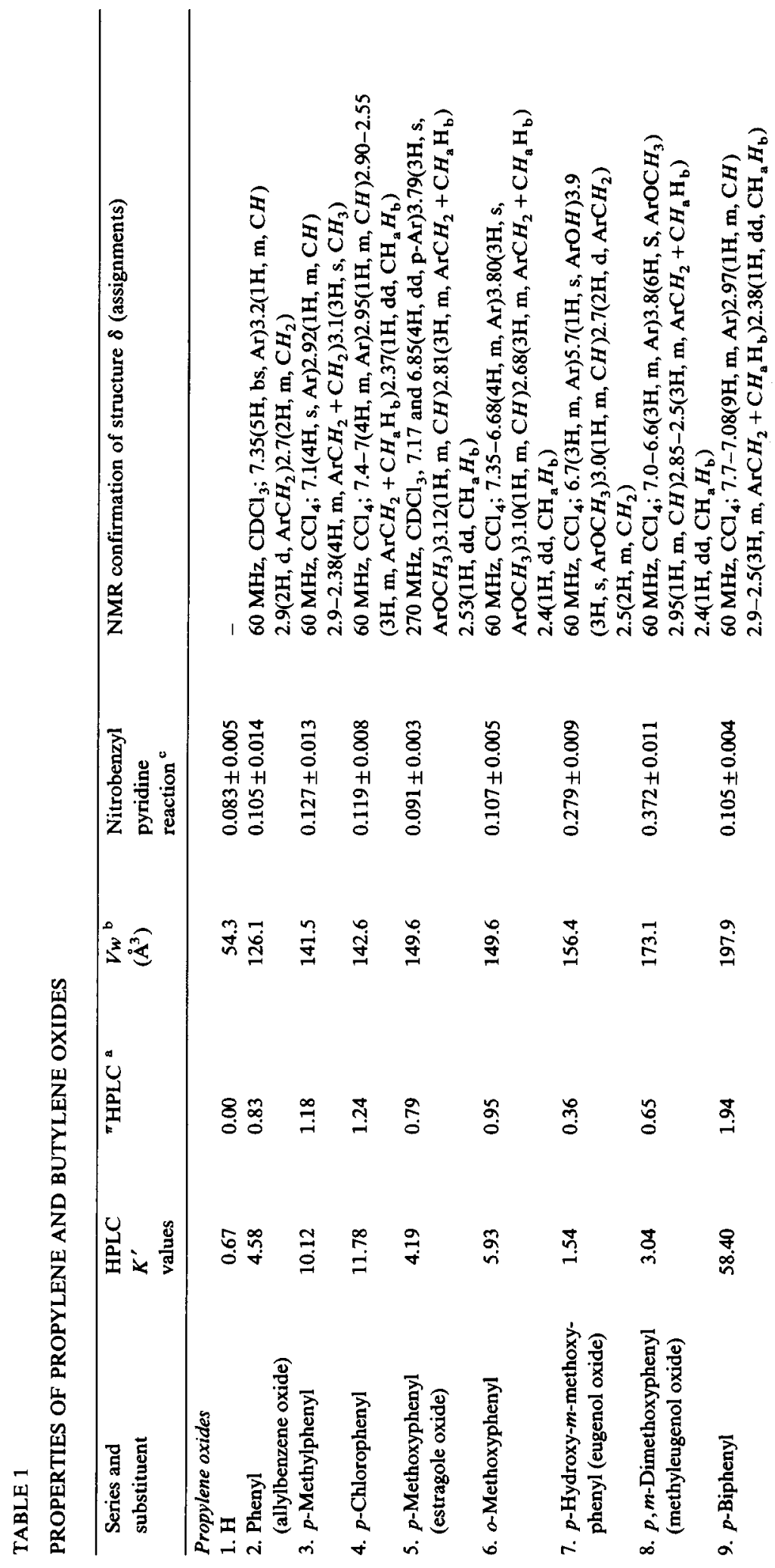




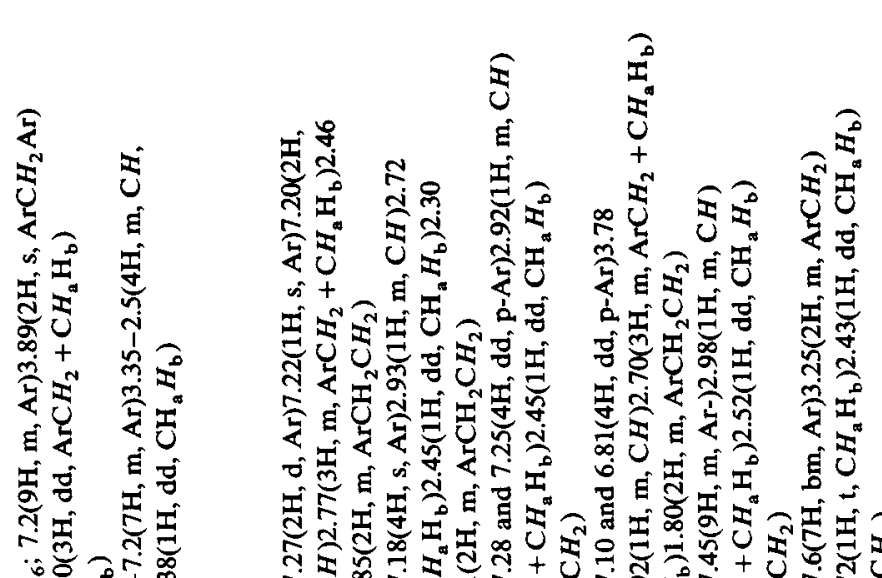

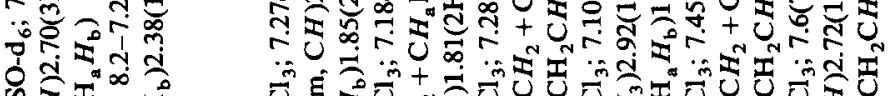

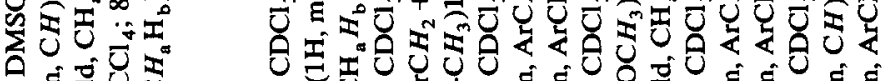

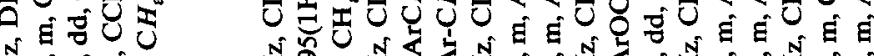

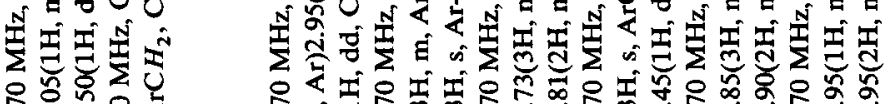

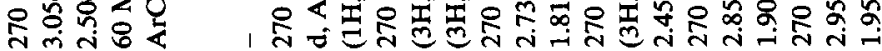

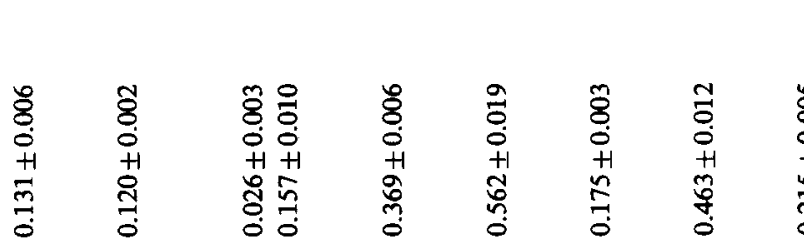

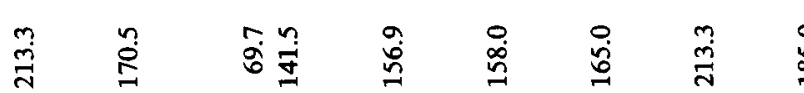

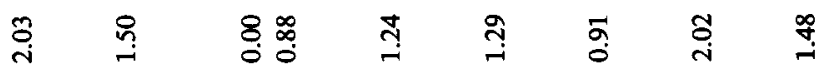

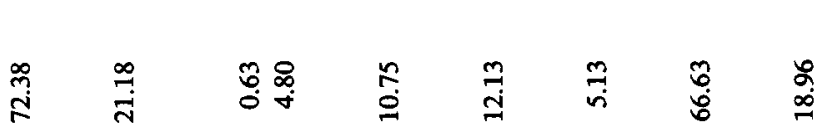

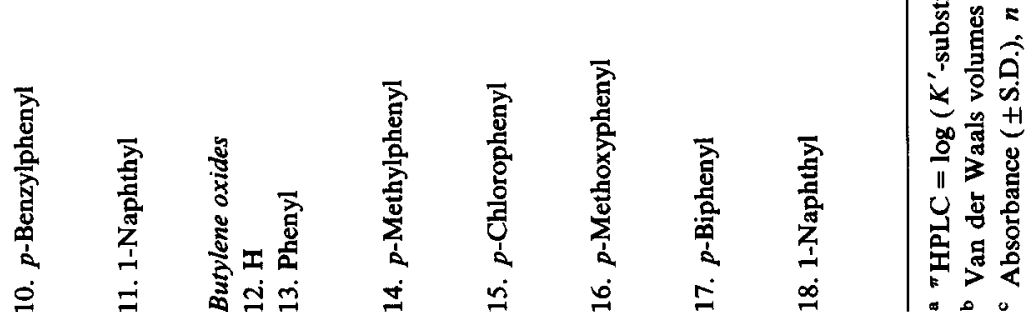


Henschler et al., 1977; De Flora, 1979). While the Ames test has established the mutagenicity of this compound, a skin-painting test yielded negative carcinogenicity results (Van Duuren et al., 1967). In comparisons of butylene oxides, Voogd et al, (1981) and Migliore et al. (1982) demonstrated that 1,2-epoxybutane was more mutagenic than the 2,3-epoxide in Klebsiella pneumoniae and Schizosaccharomyces pombe respectively.

Alkene precursors of several propylene oxides examined in the present study (Table 1) are found in flavor oils. Propylene oxide is a known mutagen (Wade et al., 1978; Pfeiffer and Dunkelberg, 1980) and carcinogen (Walpole, 1957). The epoxide precursors, eugenol, methyleugenol, and allylbenzene were all negative in the Ames assay with or without liver activation (Delaforge et al., 1977; Sekizawa and Shibamoto, 1982; Dorange et al., 1977; To et al., 1982; Swanson et al., 1979). Estragole has been found to exhibit mutagenicity with activation in TA100 (Swanson et al., 1979) but was not considered mutagenic with activation in TA1535 (To et al., 1982). Positive Ames test results have been reported for the epoxides of all four of these flavor oils (Delaforge et al., 1977; Dorange et al., 1977; Swanson et al., 1979). Carcinogenicity and/or DNA binding tests proved positive for estragole and methyleugenol but negative for eugenol (Phillips et al., 1984; Randerath et al., 1984; Drinkwater et al., 1976). Rat hepatocarcinomas were not observed for eugenol oxide and estragole oxide but mouse skin papillomas were documented (E.C. Miller et al., 1983).

\section{Materials and methods}

\section{Test compounds}

Propylene oxide, 1,2-epoxybutane (butylene oxide), glycidol, and intermediates for the synthesis of the other epoxides were purchased from Aldrich Chemical Company (Milwaukee, WI). Epoxides, as numbered in Table 1 were synthesized by the following general procedures: compounds 2 and 13, the methylene insertion reaction (Corey and Chaykovsky, 1965; Brown, 1974) with the commercially available aldehydes and trimethyl sulfoxonium iodide; compounds 5 and 7 , epoxidation with $m$-chloroperbenzoic acid (Schwartz and Blumbergs, 1964) of available allyl precursers; compounds 6 and 8, methylation with dimethyl sulfate (Bickoff et al., 1958) of the available hydroxyphenylallyl compounds followed by epoxidation with $m$-chloroperbenzoic acid; compounds $3,4,9,11,14-18$, allylation of the corresponding para-substituted phenyl bromide, or benzyl bromide using a Grignard condensation (Martin and Gleischer, 1964a) with a 0.5 mole excess of allylbromide; compound 10, the $\alpha$ phenyl-4-bromotoluene required for allylation was obtained by the method of Galun et al. (1962) through the condensation of bromobenzene and 2-hydroxy-2-phenyl-1,1,1-trichloroethane (Bergmann et al., 1950).

Epoxides were purified by distillation under reduced pressure and/or silica gel column chromatography ( $10 \%$ methylene chloride in hexane) until $2 \mu 1$ of a $10 \%$ solution of the epoxide showed a single spot on TLC (silica gel, hexane $-\mathrm{CH}_{2} \mathrm{Cl}_{2}$ 7:3) after alkylation of a 4-(4-nitrobenzyl)pyridine spray (Hammock et al., 1974). Purity (greater than $95 \%$ ) and relative capacity factors $\left(K^{\prime}\right)$ were also determined by HPLC as previously described (Rosman et al., 1986).

The epoxides were compared for their rates of alkylation of 4-(4-nitrobenzyl)pyridine at $37^{\circ} \mathrm{C}$ for $40 \mathrm{~min}$ as previously described (Hemminki and Falck, 1979; Nelis et al., 1982).

\section{Mutagenicity assay}

Dose-response relationships were determined using strains TA100 and TA1535 without S9 activation employing both the plate incorporation and preincubation assays as described by Maron and Ames (1983) with the specifications used in our laboratories for the plate incorporation (Frantz and Sinsheimer, 1981) and preincubation (Rosman et al., 1986) assays. Glycidol at $10 \mu \mathrm{mole} /$ test was used as a positive control. Each dose was run in triplicate in each system and the dose-response relationships were reconfirmed in a second set of tests.

A single concentration was selected from the linear portion of the dose-response relationship for the TA100 plate incorporation test for concurrent testing of the epoxides to compare further their relative mutagenicities. Doses of 0.5 $\mu \mathrm{mole} / \mathrm{plate}$ for the propylene oxides and 1.0 $\mu$ mole/plate for the butylene oxides were run 
together with their negative and positive controls. The concurrent evaluations were conducted with bacteria from the same overnight culture with plates run at the same time so that the comparison of data was from tests that were under greater control than was possible from the dose-response experiments.

\section{Statistical analysis}

Dunnett's many-one $t$ test (R.G. Miller, 1981) was applied to the TA100 single-dose data to compare each compound mean to the control. Tukey's method of multiple comparison (Neter and Wasserman, 1974) allowed for the determination of compound pairs having overall means significantly different from each other. Both statistical tests were conducted on square root transformations of the data. Multiple linear regression analyses were attempted on the nontransformed single-dose data.

\section{Results and discussion}

The propylene and butylene oxide compounds tested, the concentrations used, and their revertant counts are summarized in Tables 2 and 3 for strains TA100 and TA1535 in both the plate incorporation and preincubation Ames assays. While the error-prone repair strain, TA100, gave the expected overall increase in mutagenic response in comparison to TA1535, there were no outstanding differences between strains in the relative order of mutagenicities for these alkyl epoxides unlike those we previously noted for some aliphatic epoxides (Djuric et al., 1985). The lack of sensitivity and resultant difficulty in establishing relative mutagenicities was especially evident for butylene oxide and its derivatives in the preincubation tests with TA1535. In contrast to our aliphatic epoxide study, the relative order of mutagenic activity for the alkyl epoxides was similar but not identical in the plate incorporation versus the preincubation tests. However, as we previously noted for propylene oxide (Djuric et al., 1985) a comparison of the plate and preincubation tests for butylene oxide, in agreement with Canter et al. (1986), shows that it is necessary to use the closed-system preincubation test to fully establish the mutagenicities of these more volatile compounds.
It is concluded from the data in Tables 2 and 3 that all the compounds tested were active in one or more systems. The mutagenicities of the $p$-benzyl and biphenyl derivatives were the most difficult to establish because of solubility and toxicity problems. The naphthyl derivatives were the most mutagenic in all the systems. At the higher concentrations, in common with several other compounds, this mutagenicity was limited by toxicity to the bacteria as indicated by a typical reduction in background lawn with a complete lack of growth at the highest doses.

In the preincubation tests for the propylene oxide series, where any loss of effect for propylene oxide due to volatility is controlled, there is a noticeable increase in mutagenicity with the addition of the phenyl group to the parent epoxide. However, this is not the case with phenylbutylene oxide, where further isolation of the phenyl group from the epoxide results in little change in mutagenicity in comparison to butylene oxide.

In both the propylene and butylene oxide series, the effect of substitution on the phenyl ring was examined more closely in the plate incorporation test with TA100. The greatest differences among compounds were present in this system as illustrated by the means of the dose-response revertants above background in Figs. 1 and 2. As noted in these figures, concentrations of 0.5 $\mu$ mole/plate for the propylene oxides and 1.0 $\mu \mathrm{mol} /$ plate for the butylene oxides are values on the linear portion of the dose-response curves where toxicity to the bacteria would have a minimal effect. The results of the concurrent testing of each series of compounds at these concentrations run in triplicate and confirmed on separate days are summarized in Table 4 . While the parent compounds, propylene oxide and butylene oxide, were included in these series, there was no significant difference in revertants compared to their controls confirming that the plate test is not a suitable method for these more volatile compounds. Therefore, the results for these two compounds for the multiple single-dose tests were not included in subsequent evaluations.

A comparison of the results for the single-concentration tests and those summarized in Figs. 1 and 2 for the dose-response relationships shows that all propylene oxide compounds were more 


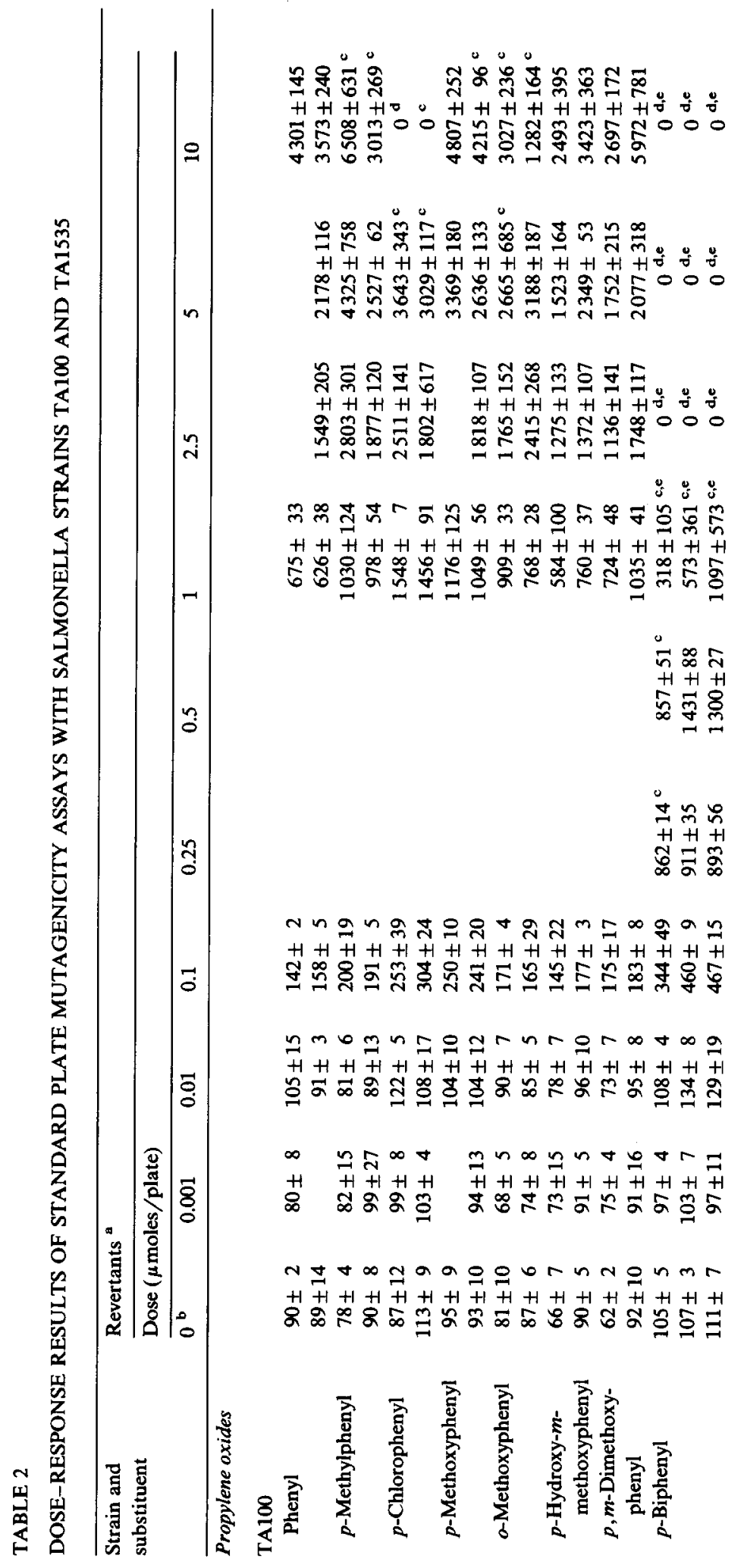




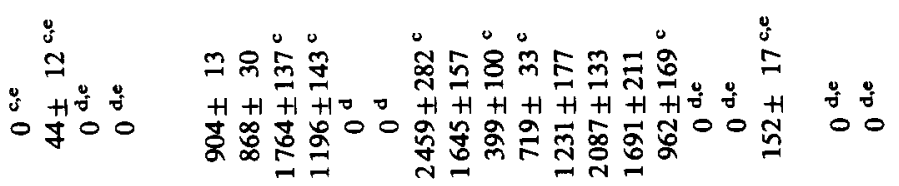

$::$

赵

$+1+1 \stackrel{0}{\square} \stackrel{0}{\circ}$

过篎。

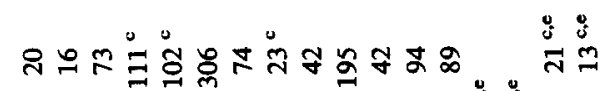

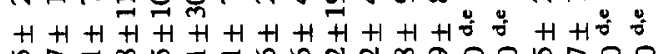

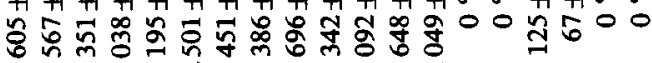

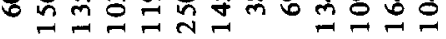

\&: :00

ช

$+1+1+1$

乎突兽

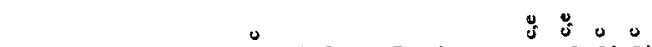

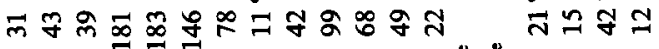

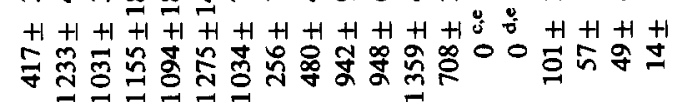
$::$

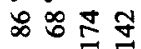

$\mathrm{H}+\mathrm{H}+\mathrm{H}$

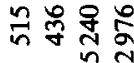

$\because: 8::$

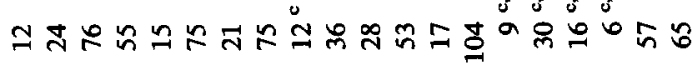
$+H+H+H+H+H+H+H+H+H+H+H+H$

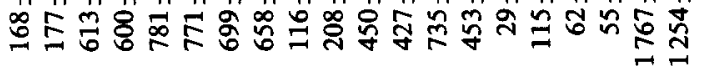

趈

H +

กิ

$$
\begin{aligned}
& \text { mo으 } \\
& \mathrm{H}+\mathrm{H}+\mathrm{H} \\
& \text { 战学 }
\end{aligned}
$$

茫

H H

$\infty \underset{+}{\infty} \sim+\mathrm{H}$

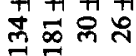

กิ

$+1+1+H$

$\infty \hat{n} 心$

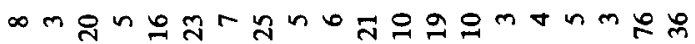
$+\mathrm{H}+\mathrm{H}+\mathrm{H}+\mathrm{H}+\mathrm{H}+\mathrm{H}+\mathrm{H}+\mathrm{H}+\mathrm{H}+\mathrm{H}+\mathrm{H}+\mathrm{H}+\mathrm{H}+\mathrm{H}$

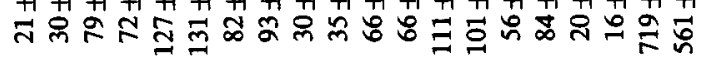

n $=9$

$+1+1+1$

$\exists \& \% 5$

mnno $+\infty$ nd $H+H$
$\forall$
$\sim$

을음

$+1+1+1$

过 20

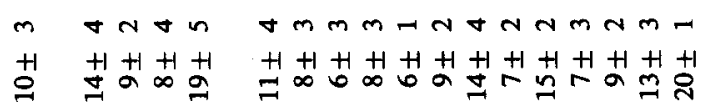

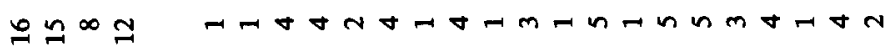

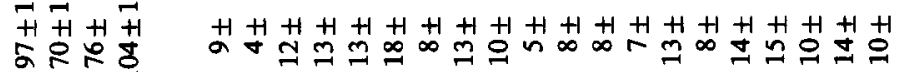
5.

离

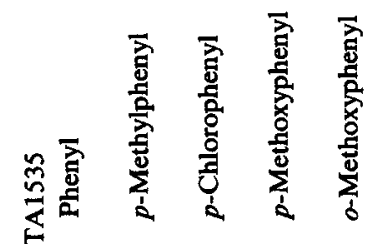

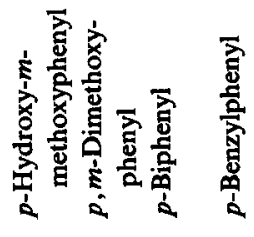

Ż̃ 


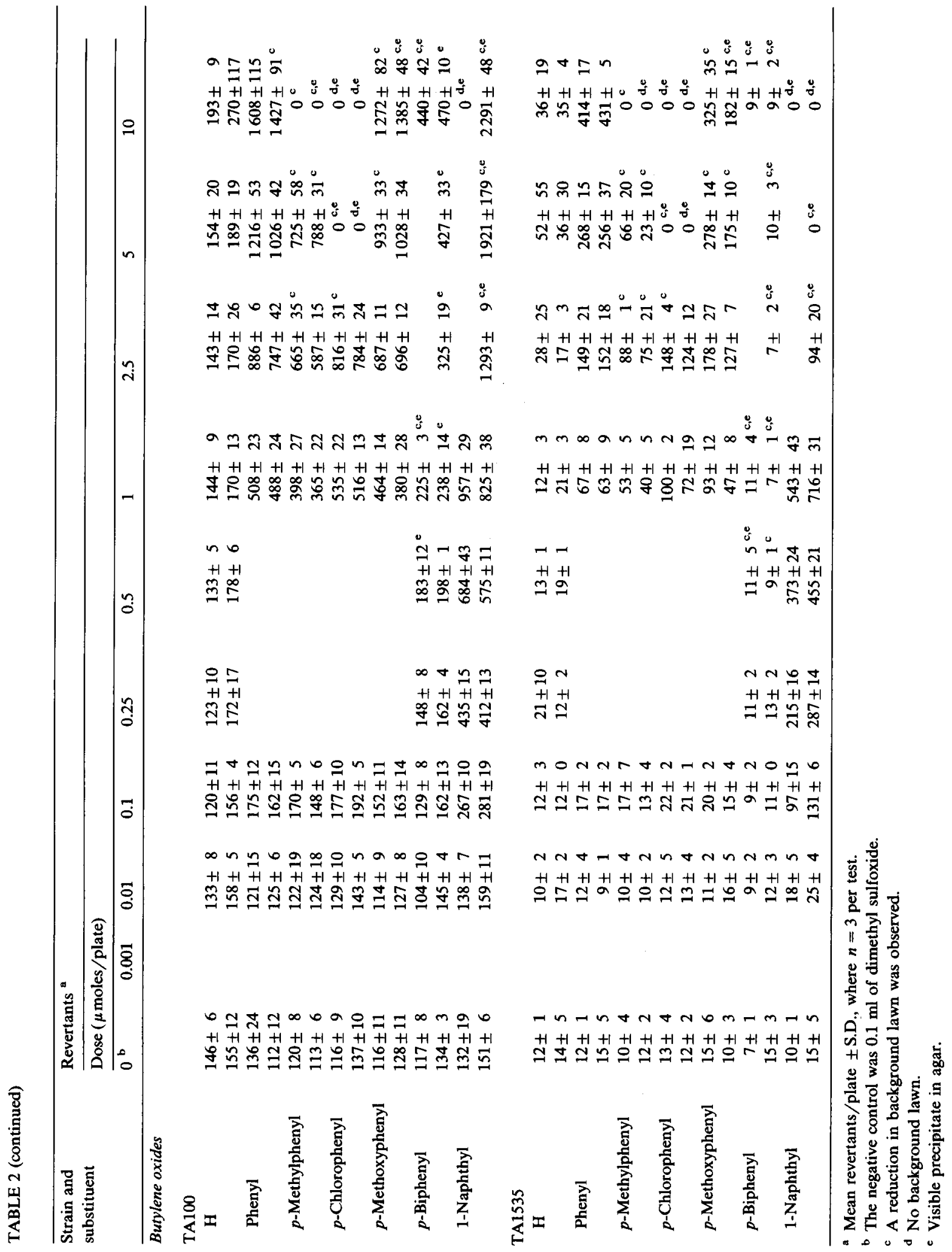




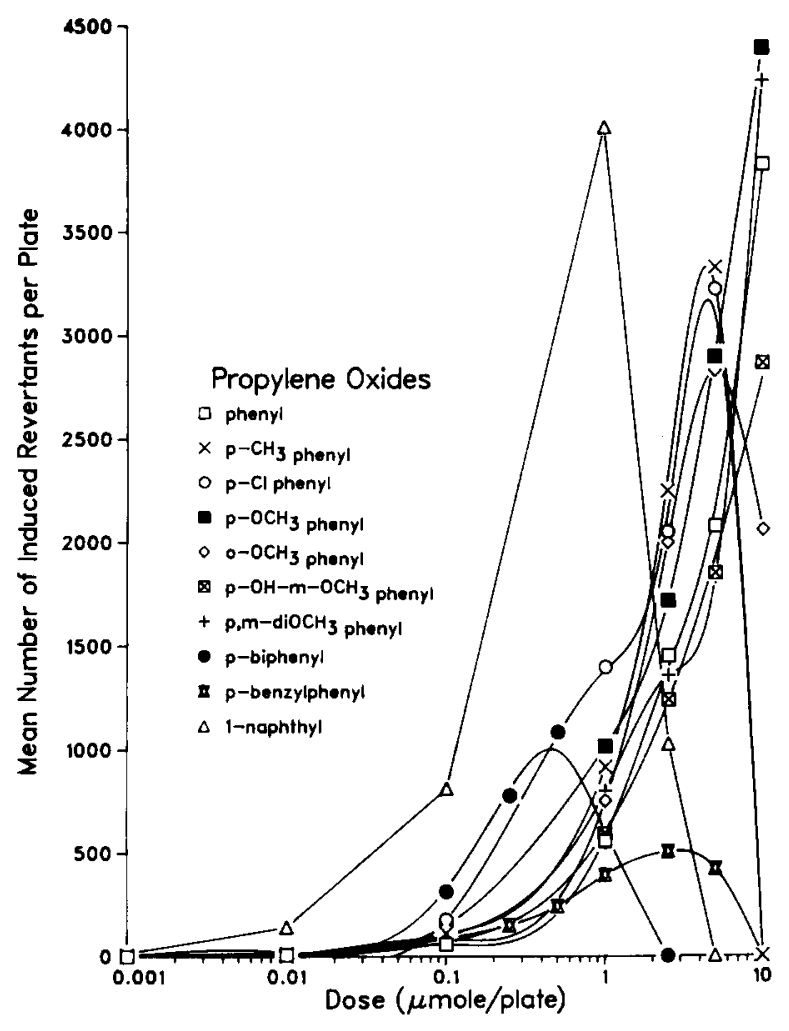

Fig. 1. Dose-mutagenicity response curves of induced revertants with Salmonella strain TA100 for propylene oxide derivatives in the standard Ames plate assay.

mutagenic than their butylene oxide counterparts. $p$-Chlorophenylpropylene oxide was included with the butylene oxide series at the $1.0 \mu \mathrm{mole} / \mathrm{plate}$ level for cross-reference to the propylene oxide series and was significantly $(p<0.01)$ more mutagenic than any of the butylene oxides. Adjusting for the differences in concentration and the response of $p$-chlorophenylpropylene oxide for the two series (Table 4), naphthylpropylene oxide was on the order of 4 times more mutagenic than naphthylbutylene oxide. The naphthyl compounds were at least twice as mutagenic as any other compound in their respective series. Thus, it was only naphthylbutylene oxide that demonstrated mutagenicity on a par with any of the propylene oxides.

Conjugated aromatic unsaturation, as represented by the naphthyl and biphenyl derivatives, could be a factor in their strong mutagenicities in

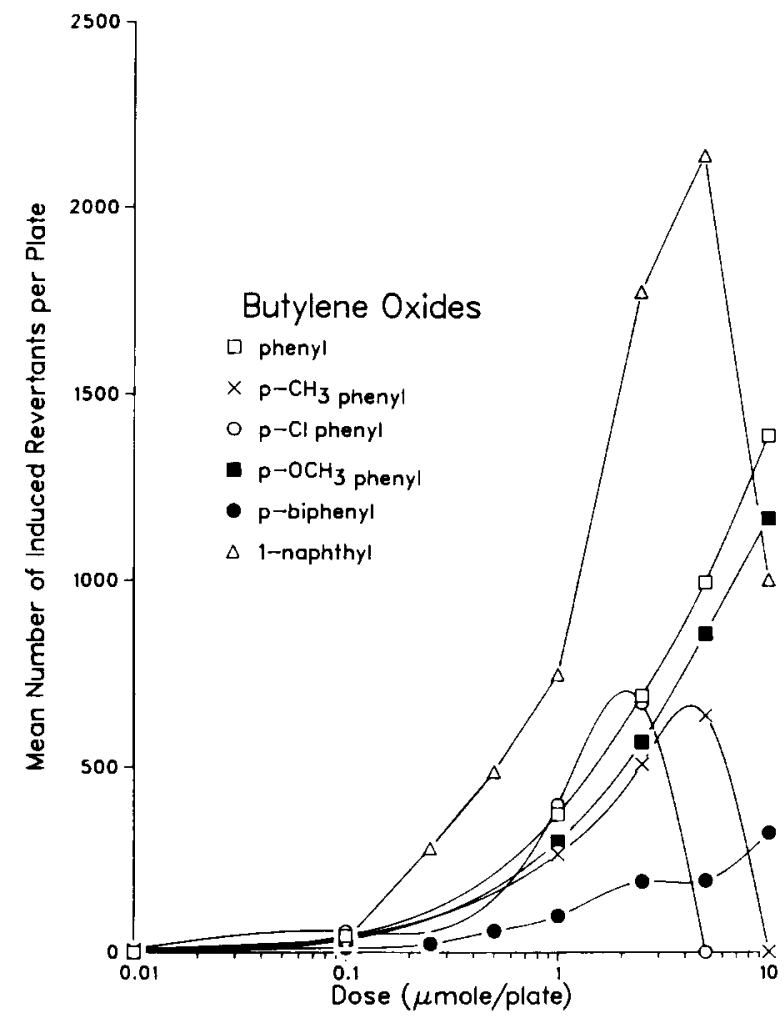

Fig. 2. Dose-mutagenicity response curves of induced revertants with Salmonella strain TA100 for butylene oxide derivatives in the standard Ames plate assay.

the propylene oxide series. The contrast of the mutagenicities of these compounds to that of the weak mutagen $p$-benzylphenylpropylene oxide, a compound of similar molecular volume and partition coefficient to that of the biphenyl derivative but where conjugation is interrupted with a methylene bridge, supports this concept. However, there is a difference in the two series in regard to the effect of extending the aromatic unsaturation as it applies to the biphenyl compounds, with the propylene oxide derivative being among the most mutagenic compounds and the biphenylbutylene oxide the least mutagenic. This is in spite of the fact that biphenylbutylene oxide is among the strongest of the alkylating agents in either series as measured by reactivity with nitrobenzylpyridine.

In general, except for the benzyl compound, substitution on the phenyl ring led to increased mutagenicity in the propylene oxide series. Com- 


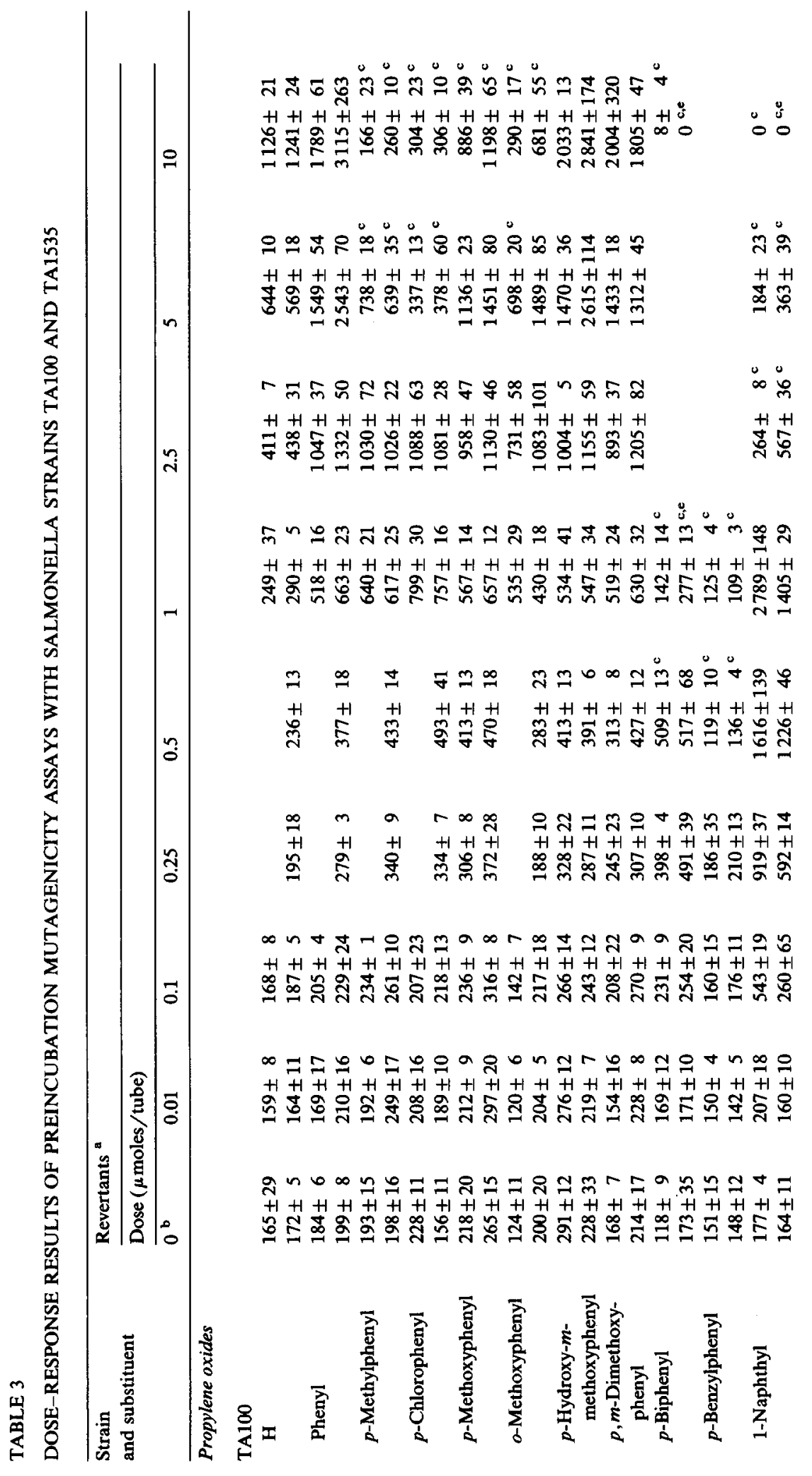




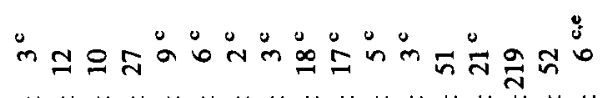
$+H+H+H+H+H+H+H+H+H+H+H$

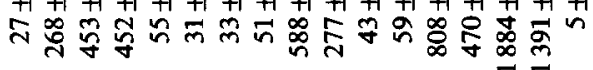

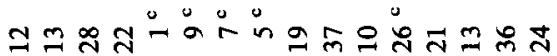
ion $H+H+H+H+H+H+H+H+H+1+H$

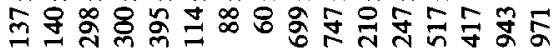

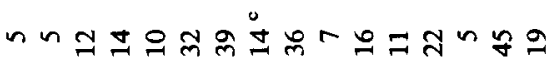
0 은으 $+\mathrm{H}+\mathrm{H}+\mathrm{H}+\mathrm{H}+\mathrm{H}+\mathrm{H}+\mathrm{H}+\mathrm{H}+\mathrm{H}+\mathrm{H}+\mathrm{H}$

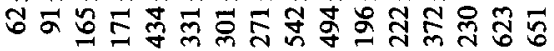

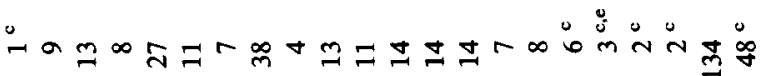
$H H+H+H+H+H+H+H+H+H+H+H+H+H$

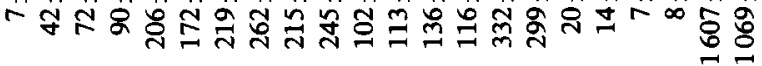

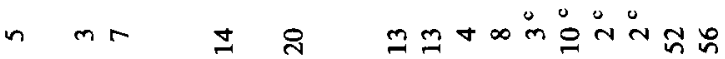

$$
\begin{aligned}
& +H+1+H \quad H+H+H+H+H+H
\end{aligned}
$$

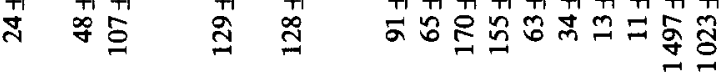

r mas a rantmoramgit

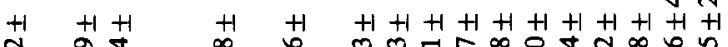
ส

mmm o m n 彳

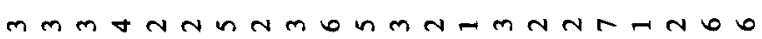
$+1+1+1+1+1+1+1+1+1+1+1+1+H+1+1+1+1+1+1$

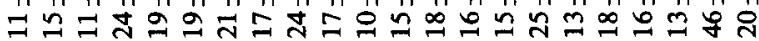

bnmm H H H H H H H H H H H H H H H H H H H H H H H 음ำป

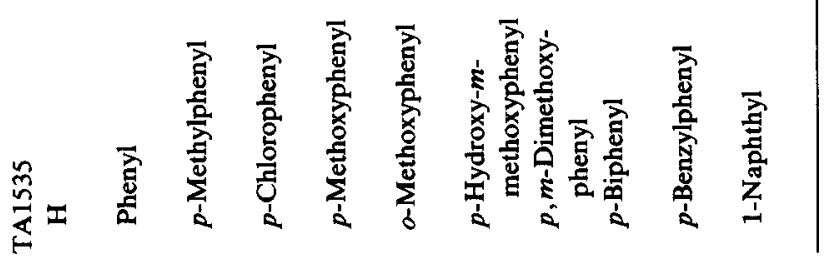




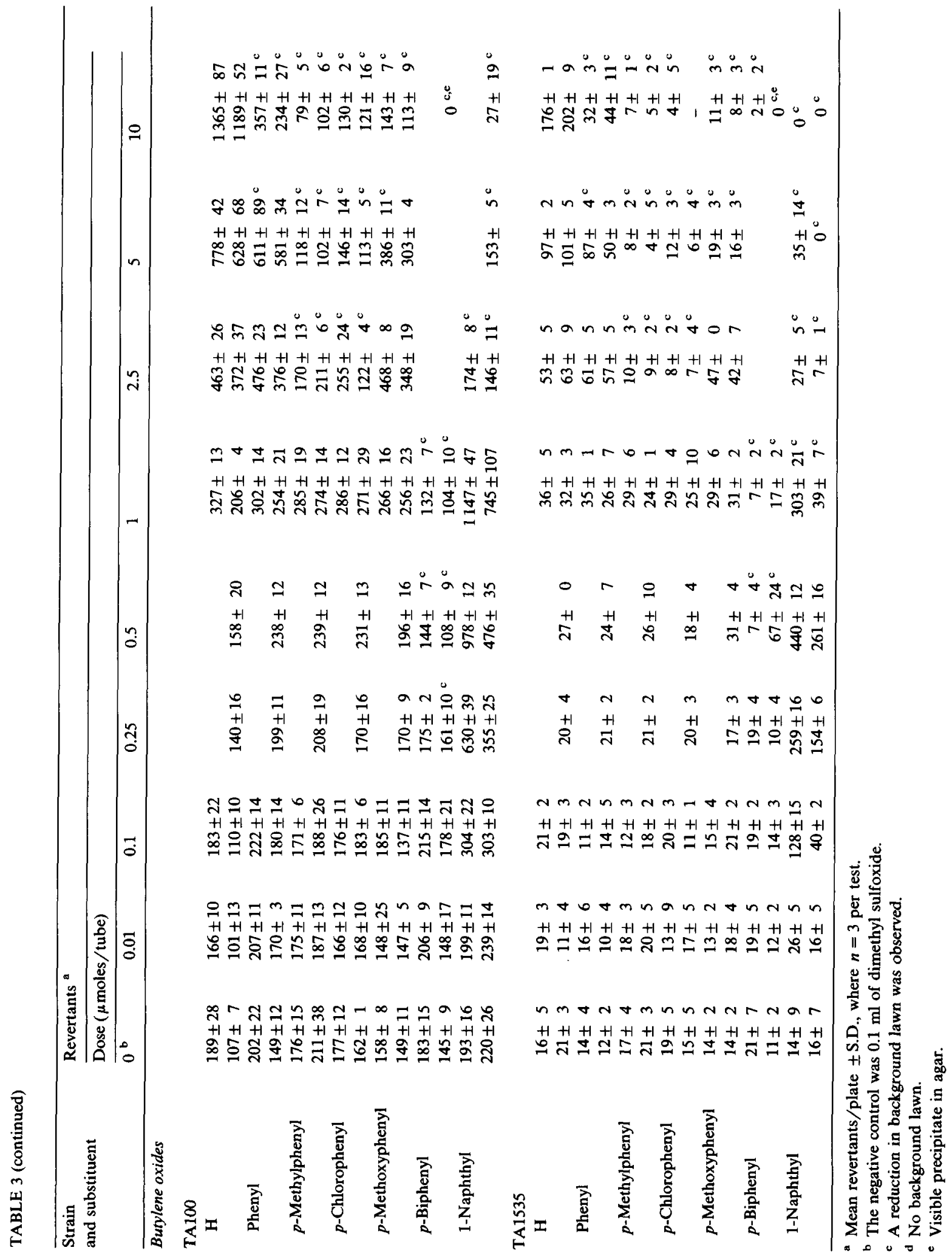


pounds ranked 1 through 5 in Table 4 are significantly $(p<0.01)$ more mutagenic than phenylpropylene oxide. This was not the case with the butylene oxides where only the naphthyl derivative had significantly $(p<0.01)$ greater mutagenicity than phenylbutylene oxide.

Hammett values as a measure of the effect of substituent groups on chemical reactivity are available for the unsubstituted phenyl derivative as well as the p-chloro-, phenyl-, methyl- and methoxy-substituted compounds (McDaniel and Brown, 1958). The correlation of mutagenicity (Table 4) to these values is poor in both the propylene oxide series $(r=0.243, n=45)$ and for the butylene oxides $(r=0.241, n=30)$. This is in direct contrast to our results for a series of 7 phenylglycidyl ethers (Neau et al., 1982) where, with an oxygen replacing the methylene group attached to the oxirane ring, there is a strong positive correlation of mutagenicity to Hammett values.

Four of the phenylpropylene oxide compounds tested in the present investigation, the $p$-methoxy, the $p$-hydroxy-m-methoxy, $p, m$-dimethoxy and phenylpropylene oxide are the epoxides of the naturally occurring flavor oils, estragole, eugenol, methyleugenol and allylbenzene respectively. We found $p$-methoxyphenylpropylene oxide to rank fourth among all the propylene oxides tested and to be significantly $(p<0.01)$ more mutagenic than the 3 other oxides of the flavor oils. Our ranking of these flavor oil epoxides in TA100 is similar to those previously reported by Dorange et al. (1977) for their plate incorporation assay results with TA1535 and is in agreement with the significantly greater mutagenicity for $p$-methoxyphenylpropylene oxide over the $p$-hydroxy- $m$-methoxyphenylpropylene derivative as reported by Swanson et al. (1979) with TA1535.

Color development upon reaction of the epoxides with 4-(4-nitrobenzyl)pyridine (Hemminki and Falck, 1979; Nelis et al., 1982) was used as a measure of the relative alkylating ability of the epoxides (Table 1). Mutagenicity values in Table 4 were examined for possible correlation to reactivity, but strong correlations were not established for the propylene oxides $(r=-0.175, n=$ $90)$ or for the butylene oxides $(r=-0.340, n=$ 36 ), Thus, some of the more mutagenic com- pounds such as the naphthyl derivatives and $p$ chlorophenylpropylene oxide were among the weaker alkylating agents, and several of the weaker mutagens such as dimethoxyphenyl- and $p$-hydroxy-m-methoxyphenylpropylene oxide or $p$ methylphenyl- and $p$-biphenylbutylene oxide were among the stronger alkylating agents.

While mutagenicity did not correlate to reactivity with nitrobenzylpyridine, it is of interest from a chemical standpoint that there are differences in reactivity depending upon the substituents present and that the magnitude of reactivity is greater for a given butylene oxide than for its corresponding propylene compound. That is, there are substitution effects even when those substituents are well removed from the epoxide site, and this effect is larger with the apparently greater separation of substituent from epoxide in the butylene series. An explanation of these effects is that the phenyl ring is bending back towards the epoxide and that this positional influence of the phenyl ring is greater in the butylene than in the propylene series. This speculation is supported by molecular models and by the greater complexity of the aromatic proton region in the NMR spectrum for phenylbutylene oxide (Table 1) than was anticipated. These observations are also consistent with the conclusions of Martin and Gleischer (1964a, b) that the reactivity of the parent phenylalkenes of our epoxides are affected by the $\pi$-cloud of the phenyl ring and that the effect was maximal for their butylene compounds.

Possible correlations of mutagenicity to the molecular volumes of the compounds (Table 1) were lacking for both the propylene oxide $(r=$ $0.137)$ and butylene oxide series $(r=0.107)$. Likewise, correlations of mutagenicity to partition coefficients (Table 1 ) for the propylene oxide $(r=$ $0.342)$ and butylene oxide series $(r=0.026)$ were poor. Therefore, since it was not possible to establish strong correlations of mutagenicity to any of the above factors, it was also not possible to write a meaningful regression model in terms of these values. This differs from the studies with styrene oxides (Tamura et al., 1982; Rosman et al., 1986) where there were relatively weak correlations to reactivity as indicated by Hammett values but strong correlations to molecular volume.

The classical structure-activity parameters were 
TABLE 4

SINGLE DOSE COMPARISONS FOR SALMONELLA STRAIN TA100 IN THE STANDARD PLATE ASSAY

\begin{tabular}{|c|c|c|c|}
\hline Substituent & $\begin{array}{l}\text { Mean } \\
\pm \text { S.D. }\end{array}$ & Rank $^{b}$ & $\begin{array}{l}\text { Signifi- } \\
\text { cance }^{c}\end{array}$ \\
\hline \multicolumn{4}{|c|}{ Propylene oxide series: $0.5 \mu$ mole / plate } \\
\hline \multicolumn{4}{|l|}{ Control } \\
\hline DMSO & $\begin{array}{ll}95 \pm & 8 \\
92 \pm & 6 \\
98 \pm & 3\end{array}$ & 12 & \\
\hline \multicolumn{4}{|l|}{ Test compounds } \\
\hline 1-Naphthyl & $\begin{array}{l}3.427 \pm 596 \\
1923 \pm 107 \\
3572 \pm 285\end{array}$ & 1 & $0.0000^{*}$ \\
\hline$p$-Biphenyl & $\begin{array}{l}1071 \pm 37 \\
1450 \pm 52 \\
1584 \pm 36\end{array}$ & 2 & $0.0043^{*}$ \\
\hline p-Chlorophenyl & $\begin{array}{r}913 \pm 26 \\
1208 \pm 130 \\
1135 \pm 27\end{array}$ & 3 & $0.0082^{*}$ \\
\hline$p$-Methoxyphenyl & $\begin{array}{r}710 \pm 28 \\
1026 \pm 39 \\
836 \pm 23\end{array}$ & 4 & 0.4008 \\
\hline p-Methylphenyl & $\begin{array}{l}843 \pm 36 \\
761 \pm 32 \\
757 \pm 32\end{array}$ & 5 & $0.0252 *$ \\
\hline o-Methoxyphenyl & $\begin{array}{l}604 \pm 37 \\
642 \pm 33 \\
621 \pm 34\end{array}$ & 6 & 0.3635 \\
\hline $\begin{array}{l}p \text {-Hydroxy-m-met } \\
\text { oxyphenyl }\end{array}$ & $\begin{array}{l}682 \pm 11 \\
434 \pm 12 \\
583 \pm 6\end{array}$ & 7 & 0.7449 \\
\hline $\begin{array}{l}p, m \text {-Dimethoxy- } \\
\text { phenyl }\end{array}$ & $\begin{array}{l}564 \pm 44 \\
433 \pm 14 \\
635 \pm 19\end{array}$ & 8 & 0.2848 \\
\hline Phenyl & $\begin{array}{l}475 \pm 19 \\
429 \pm 27 \\
523 \pm 26\end{array}$ & 9 & 0.1348 \\
\hline p-Benzylphenyl & $\begin{array}{l}394 \pm 19 \\
391 \pm 16 \\
383 \pm 21\end{array}$ & 10 & $0.0000^{*}$ \\
\hline $\mathbf{H}$ & $\begin{array}{l}98 \pm 16 \\
98 \pm 20 \\
92 \pm 6\end{array}$ & 11 & 0.9775 \\
\hline
\end{tabular}

Butylene oxide series: $1.0 \mu$ mole / plate

Control

DMSO

$91 \pm 10$

$102 \pm 6$

p-Chlorophenyl-

propylene oxide

$2041 \pm 25$

$1681 \pm 70$

Test compounds

1-Naphthyl

$1422 \pm 42$

$1239 \pm 34$

$454 \pm 15$

$495 \pm 19$
TABLE 4 (continued)

\begin{tabular}{|c|c|c|c|}
\hline Substituent & $\begin{array}{l}\text { Mean } \\
\pm \text { S.D. }\end{array}$ & Rank $^{b}$ & $\begin{array}{l}\text { Signifi- } \\
\text { cance }\end{array}$ \\
\hline Phenyl & $\begin{array}{l}407 \pm 7 \\
445 \pm \quad 9\end{array}$ & 4 & 0.3785 \\
\hline p-Methoxyphenyl & $\begin{array}{l}418 \pm 29 \\
379 \pm 23\end{array}$ & 5 & 0.2533 \\
\hline p-Methylphenyl & $\begin{array}{l}308 \pm 5 \\
424 \pm 40\end{array}$ & 6 & $0.0000 *$ \\
\hline$p$-Biphenyl & $\begin{array}{l}224 \pm 12 \\
241 \pm 15\end{array}$ & 7 & $0.0000 *$ \\
\hline $\mathbf{H}$ & $\begin{array}{lr}100 \pm & 6 \\
105 \pm & 16\end{array}$ & 8 & 0.6992 \\
\hline
\end{tabular}

a Each trial included 3 replicate plates.

b Ranks were determined using the mean of the revertants from all experimental trials.

c Based on Tukey's pairwise comparisons of square-root transformed data.

* Indicates the mean of the revertants for this compound is significantly different from the mean for the next highest ranked derivative.

inadequate descriptors of aryloxide mutagenicity. The degree of conjugated aromatic unsaturation may provide a better lead to evaluating mutagenic potency in this study. Sugiura and Goto (1983) have reported enhanced mutagenicity for glycidyl ethers with increased aromaticity. In agreement with the present investigation, this effect was reduced when the aromatic groups were further separated from the epoxide moiety by an ethylene vs. a methylene bridge.

\section{Acknowledgements}

The authors express their appreciation to Dr. Bruce Ames, University of California at Berkeley for supplying Salmonella strains TA100 and TA1535.

This investigation was supported by Grant R01 ES03345 from the National Institute of Environmental Health Sciences DHHS.

\section{References}

Bergmann, E.D., D. Ginsburg and D. Lavie (1950) Aryltrichloromethylcarbinols, J. Am. Chem. Soc., 72, 5012-5014.

Bickoff, E.M., R.L. Lyman, A.L. Livingston and A.N. Roth (1958) Characterization of coumestrol, a naturally occurring plant estrogen, J. Am. Chem. Soc., 80, 3969-3971.

Brown, C.A. (1974) Potassium hydride, a highly active new hydride reagent, Reactivity, applications, and techniques in organic and organometallic reactions, J. Org. Chem., 39, 3913-3918. 
Canter, D.A., E. Zeiger, S. Haworth, T. Lawlor, K. Mortelmans and W. Speck (1986) Comparative mutagenicity of aliphatic epoxides in Salmonella, Mutation Res., 172, 105-138.

Carlson, R.M., R.E. Carlson and H.L. Kopperman (1975) Determination of partition coefficients by liquid chromatography, J. Chromatogr., 107, 219-223.

Chen, C.C., W.T. Speck and H.S. Rosenkranz (1975) Mutagenicity testing with Salmonella typhimurium strains, II. The effect of unusual phenotypes on the mutagenic response, Mutation Res., 28, 31-35.

Corey, E.J., and M. Chaykovsky (1965) Dimethyloxosulfoxonium methylide and dimethylsulfonium methylide formation and application to organic synthesis, J. Am. Chem. Soc., 87, 1353-1364.

De Flora, S. (1979) Metabolic activation and deactivation of mutagens and carcinogens, Ital. J. Biochem., 28, 81-103.

Delaforge, M., P. Janiaud, J.L. Dorange, J.P. Morizot and P. Padieu (1977) Activation métabolique d'un promutagène naturel, l'eugénol, par des cultures réplicatives de cellules épithéliales de foie de rat adulte, C.R.S. Soc. Biol., 171, 100-107.

Djuric, Z., B.H. Hooberman, L. Rosman and J.E. Sinsheimer (1985) Reactivity of mutagenic propylene oxides with deoxynucleosides and DNA, Environ. Mutagen., 8, 369-383.

Dorange, J.L., M. Delaforge, P. Janiaud and P. Padieu (1977) Pouvoir mutagène de métabolites de la voie époxyde-diol du safrol et d'analogues, Etude sur Salmonella typhimurium, C.R.S. Soc. Biol., 171, 1041-1048.

Drinkwater, N.R., E.C. Miller, J.A. Miller and H.C. Pitot (1976) Hepatocarcinogenicity of estragole (1-allyl-4methoxybenzene) and 1'-hydroxyestragole in the mouse and mutagenicity of $1^{\prime}$-acetoxyestragole in bacteria, J. Natl. Cancer Inst., 57, 1323-1330.

Frantz, S.W., and J.E. Sinsheimer (1981) Bacterial mutagenicity and toxicity of cycloaliphatic epoxides, Mutation Res., 90, 67-78.

Galun, A.B., A. Kaluszyner and E.D. Bergmann (1962) Homologs of diphenylmethane, I. Homologs with an even number of rings, J. Org. Chem., 27, 1426-1430.

Gervasi, P.G., L. Citti, M. Del Monte, V. Longo and D. Benetti (1985) Mutagenicity and chemical reactivity of epoxidic intermediates of the isoprene metabolism and other structurally related compounds, Mutation Res., 156, $77-82$.

Hammock, L.G., B.D. Hammock and J.E. Cassida (1974) Detection and analysis of epoxides with 4-( $p$-nitrobenzyl)pyridine, Bull. Environ. Contam. Toxicol., 12, 759-764.

Hemminki, K., and K. Falck (1979) Correlation of mutagenicity and 4-( $p$-nitrobenzyl)-pyridine alkylation by epoxides, Toxicol. Lett., 4, 103-106.

Hemminki, K., K. Falck and H. Vainio (1980) Comparison of alkylation rates and mutagenicity of directly acting industrial and laboratory chemicals, Arch. Toxicol., 46, $277-285$.

Henschler, D., E. Eder, T. Neudecker and M. Metzler (1977) Carcinogenicity of trichloroethylene: fact or artifact?, Arch. Toxicol., 37, 233-236.
Katz, M., S. Kazmer and D. Weinstein (1980) An analysis of weak mutagens in the Ames assay, J. Environ. Pathol. Toxicol., 3, 171-187.

Maron, D.M., and B.N. Ames (1983) Revised methods for the Salmonella mutagenicity test, Mutation Res., 113, 173-215.

Martin, M.M., and G.J. Gleischer (1964a) The addition of the trichloromethyl radical to substituted 3-phenyl-1-propenes and 4-phenyl-1-butenes, J. Am. Chem. Soc., 86, 233-238.

Martin, M.M., and G.J. Gleischer (1964b) The addition of the trichloromethyl radical to w-phenylalkenes, J. Am. Chem. Soc., 238-241.

McDaniel, D.H., and H.C. Brown (1958) An extended table of Hammett substituent constants based on ionization of substituted benzoic acids, J. Org. Chem., 420-427.

Migliore, L., A.M. Rossi and N. Loprieno (1982) Mutagenic action of structurally related alkene oxides on Schizosaccharomyces pombe: The influence, 'in vitro', of mouse-liver metabolizing system, Mutation Res., 102, 425-437.

Miller, E.C., A.B. Swanson, D.H. Phillips, T.L. Fletcher, A. Liem and J.A. Miller (1983) Structure-activity studies of the carcinogenicities in the mouse and rat of some naturally occurring and synthetic alkenylbenzene derivatives related to safrole and estragole, Cancer Res., 43, 1124-1134.

Miller Jr., R.G. (1981) Simultaneous Statistical Inference, 2nd Edn., Springer, New York, pp. 76-81.

Moriguchi, I., Y. Kanada and K. Komatsu (1976) Van der Waals volume and the related parameters for hydrophobicity in structure-activity studies, Chem. Pharm. Bull., 24, 1799-1806.

Neau, S.H., B.H. Hooberman, S.W. Frantz and J.E. Sinsheimer (1982) Substituent effects on the mutagenicity of phenyl glycidyl ethers in Salmonella typhimurium. Mutation Res., 93, 297-304.

Nelis, H.J.C.F., S.C. Airy and J.E. Sinsheimer (1982) Comparison of the alkylation of nicotinamide and 4-( $p$ nitrobenzyl)-pyridine for the determination of aliphatic epoxides. Anal. Chem., 54, 213-216.

Neter, J., and W. Wasserman (1974) Applied Linear Statistical Models, Irwin, Homewood IL, pp. 474-482, 507-508.

Pfeiffer, E.H., and H. Dunkelberg (1980) Mutagenicity of ethylene oxide and propylene oxide and of the glycols and halohydrins formed from them during fumigation of foodstuffs, Food Cosmet. Toxicol., 18, 115-118.

Phillips, D.H., M.V. Reddy and K. Randerath (1984) ${ }^{32}$ PPost-labelling analysis of DNA adducts formed in the livers of animals treated with safrole, estragole and naturally-occurring alkenylbenzenes, II. Newborn male $\mathrm{B} 6 \mathrm{C} 3 \mathrm{~F}_{1}$ mice, Carcinogenesis, 5, 1623-1628.

Randerath, K., R.E. Haglund, D.H. Phillips and M.V. Reddy (1984) ${ }^{32}$ P-Post-labelling analysis of DNA adducts formed in the livers of animals treated with safrole, estragole and other naturally-occurring alkenylbenzenes, I. Adult female CD-1 mice, Carcinogenesis, 5, 1623-1628.

Rosenkranz, H.S., and W.T. Speck (1976) Activation of nitrofurantoin to a mutagen by rat liver nitroreductase, Biochem. Pharmacol., 25, 1555-1556.

Rosman, L.B., V.G. Gaddamidi, B.H. Hooberman and J.E. Sinsheimer (1986) Mutagenicity of para-substituted $\alpha$ - 
methylstyrene oxide derivatives with Salmonella, Mutation Res., 171, 63-70.

Schwartz, N.M., and J.H. Blumbergs (1964) Epoxidations with $m$-chlorobenzoic acid, J. Org. Chem., 29, 1976-1979.

Sekizawa, J., and T. Shibamoto (1982) Genotoxicity of safrole-related chemicals in microbial test systems, Mutation Res., 101, 127-140.

Sugiura, K., and M. Goto (1981) Mutagenicities of styrene oxide derivatives on bacterial test systems: relationship between mutagenic potencies and chemical reactivity, Chem.-Biol. Interact., 35, 71-91.

Sugiura, K., and M. Goto (1983) Mutagenicities of glycidyl ethers for Salmonella typhimurium: relationship between mutagenic potencies and chemical reactivity, Chem.-Biol. Interact., 45, 153-169.

Sugiura, K., T. Kimura and M. Goto (1978a) Mutagenicities of styrene oxide derivatives on Salmonella typhimurium (TA100), Relationship between mutagenic potencies and chemical reactivity, Mutation Res., 58, 159-165.

Sugiura, K., S. Yamanaka, S. Fukasawa and M. Goto (1978b) The mutagenicity of substituted and unsubstituted styrene oxides in $E$. coli: relationship between mutagenic potencies and physico-chemical properties, Chemosphere, 9, 737-742.

Swanson, A.B., D.D. Chambliss, J.C. Blomquist, E.C. Miller and J.A. Miller (1979) The mutagenicities of safrole, estragole, eugenol, trans-anethole, and some of their known or possible metabolites for Salmonella typhimurium mutants, Mutation Res., 60, 143-153.

Tamura, N., K. Takahashi, N. Shirai and Y. Kawazoe (1982) Studies on chemical carcinogens, XXI. Quantitative structure-mutagenicity relationship among substituted styrene oxides, Chem. Pharm. Bull., 30, 1393-1400.

To, L.P., T.P. Hunt and M.E. Andersen (1982) Mutagenicity of trans-anethole, estragole, eugenol, and safrole in the Ames Salmonella typhimurium assay, Bull. Environ. Contam. Toxicol., 28, 647-654.

Van Duuren, B.L., L. Langseth, B.M. Goldsmidt and L. Orris (1967) Carcinogenicity of epoxides, lactones and peroxy compounds, VI. Structure and carcinogenic activity, J. Natl. Cancer Inst., 39, 1217-1228.

Voogd, C.E., J.J. van der Stel and J.J.J.A.A. Jacobs (1981) The mutagenic action of aliphatic epoxides, Mutation Res., 89, 269-282.

Wade, D.R. S.C. Airy and J.E. Sinsheimer (1978) Mutagenicity of aliphatic epoxides, Mutation Res., 58, 217-223.

Walpole, A.L. (1957) Carcinogenic action of alkylating agents, Ann. N.Y. Acad. Sci., 68, 750-761. 